\title{
Erratum to: Analytical two-dimensional modeling of hydrogen-air mixture in catalytic micro-combustor
}

\author{
S. A. Fanaee · J. A. Esfahani
}

Published online: 20 October 2015

(C) Springer Science+Business Media Dordrecht 2015

\section{Erratum to: Meccanica (2015) 50:1717-1732 DOI 10.1007/s11012-015-0118-z}

Acknowledgments We highly appreciate Khorasan Razavi Gas Co. for their technical and financial support to this research.

The authors would like to apologize for the fact that the below-mentioned acknowledgment was not included in the published article.

The online version of the original article can be found under doi:10.1007/s11012-015-0118-z.

\section{S. A. Fanaee $(\bowtie)$}

Mechanical Engineering Department, University of Birjand, 81746-73441 Birjand, Iran

e-mail: sab.famech@gmail.com

\section{J. A. Esfahani}

Mechanical Engineering Department, Center of Excellence on Modelling and Control Systems (CEMCS), Ferdowsi University of Mashhad, 91775-11111 Mashhad, Iran

e-mail: Abolfazl@um.ac.ir 